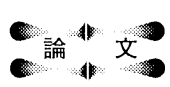

\title{
岸素材料のヤング率と熱伝導率に及ぼす圧縮予応力の影響
}

\author{
奥 達雄*, 中田昌幸**, 車田 亮***, 川又清弘***
}

(可成12年7月24日受理, 平成12年8月28日採択)

\section{Effect of Compressive Prestress on Young's Modulus and Thermal Conductivity of Carbon Materials}

\begin{abstract}
Tatsuo Oku*, Masayuki Nakata**, Akira Kurumada***and Kiyohiro Kawamata***
Effect of compressive prestress on the correlation between thermal conductivity and Young's modulus of carbon materials, fine-grained isotropic graphite IG-430U and a felt type C/C composite CX-2002U, was examined. Young's modulus and thermal conductivity decreased due to compressive prestress. The change in thermal conductivity of carbon materials was related to that of Young's modulus via sound velocity. The decrease in thermal conductivity of IG-430U graphite due to prestress was mostly correlated with that in Young's modulus. Also, decrease in thermal conductivity of $\mathrm{C} / \mathrm{C}$ composite showed the similar tendency as the case for the graphite.
\end{abstract}

KEYWORDS : Carbon, Prestress, Young's modulus, Thermal conductivity

\section{1. 緒 言}

炭素系材料は圧縮応力を受けると, とくにその応力が圧縮 強さの $60 \%$ 以上になったとき, き裂の発生, 結晶子の回転等が 生じて, 応力付加方向およびそれに垂直な方向のヤング率が 減少する(1)-5)。これは, 圧縮応力付加に伴う微細構造の変化を 反映した結果である。炭素系材料に压縮応力を付加した結 果, き裂が発生したり, 結晶子が回転したりするとヤング率ば かりでなく他の物理的性質たとえば熱伝導率も変化する可能 性がある(6)。炭素系材料を構造材料等に使用するとき, 構造健 全性を確認する上で, 構造物内の発生応力を評価することが 必要になる場合がある。ヤング率や熱伝導率は発生応力の評 価に必要となる特性である。これらの值が変化するというこ とは圧縮応力がかかることによって, 構造物内に発生する応 力が変化するということを意味する。構造物内の発生応力の 評価は構造物の安全性評価に直結するので, 大変重要なこと であり, 圧縮応力付加に伴うヤング率や熱伝導率の変化を定 量的に把握しておくことは, 構造健全性を確認する上で大切 なことである。一方, 炭素材料では, 熱伝導は大部分フォノン 伝導によるものとされている。したがって, ヤング率と熱伝導 率の間には音速という共通の因子が存在することがわかる。

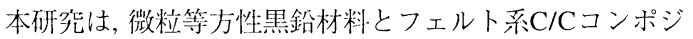
ットに圧縮応力を付加した前後のヤング率と熱伝導特性の変 化を調べるとともに, それらの間の相関性についても検討を 加えた結果をまとめたものである。

\section{2. 実験方法}

供試材料は微粒等方性黑鉛IG-430Uおよびフェルト系C/C 複合材料CX-2002Uであり，ともに東洋炭素(株製である。こ れらの材料の代表特性をTable 1に示す。

最初の試験片の大きさは $18 \times 18 \times 30 \mathrm{~mm}^{3}$ であっだこの 試験片の $30 \mathrm{~mm}$ の方向にそれぞれの材料の平均圧縮強さの $90 \%$ 応力を付加した。その後 $30 \mathrm{~mm}$ 方向について $5 \mathrm{MHz} の$

Table 1 Materials tested.

\begin{tabular}{|c|c|c|}
\hline Tested Materials & $\begin{array}{c}\text { Bulk } \\
\text { Density } \\
\left(\mathrm{g} / \mathrm{m}^{3}\right)\end{array}$ & $\begin{array}{c}\text { Electrical } \\
\text { Resistivity } \\
(\mu \Omega \cdot \mathrm{m})\end{array}$ \\
\hline $\mathrm{IG}-430$ & 1.82 & 9.7 \\
\hline $\mathrm{CX}-2002 \mathrm{U}$ & 1.67 & $1.7(\mathrm{XX})$ \\
$(\mathrm{XX}, \mathrm{YY}, \mathrm{ZZ})$ & & $3.4(\mathrm{YY})$ \\
& & $5.1(\mathrm{ZZ})$ \\
\hline
\end{tabular}

* 茨城大学工学部, 現在, 放送大学・茨城学習センター：テ310-0056 水戸市文京2-1-1 茨城大学内

* The Ibaraki Study Center, The University of the Air : 2-1-1 Bunkyo, Mito 310-0056, Japan

** 茨城大学理工学研究科博士前期課程, 現在, 大阪大学大学院博士後期課程

** Graduate School Student, Ibaraki University, Now in Osaka University

*** 茨城大学工学部： $7316-8511$ 日立市中成沢町4-12-1

*** Faculty of Engineering, Ibaraki University : 12-1 Nakanarusawa 4-chome, Hitachi 316-8511, Japan 
Table 2 Changes in Young's modulus and electrical resistivity of IG-430U (stress axis:L).

\begin{tabular}{|c|c|c|c|c|c|c|c|}
\hline \multirow[t]{2}{*}{ Specimen } & \multicolumn{2}{|c|}{$\begin{array}{c}\text { Young's } \\
\text { Modulus (GPa) }\end{array}$} & \multirow{2}{*}{$\begin{array}{c}\text { Changes in } \\
\text { Density } \\
\Delta \rho / \rho(\%)\end{array}$} & \multirow{2}{*}{$\begin{array}{c}\text { Changes in } \mathrm{E} \\
\Delta \mathrm{E} / \mathrm{E}_{0}(\mathrm{~L}) \\
(\%)\end{array}$} & \multirow{2}{*}{$\begin{array}{c}\text { Changes in } \mathrm{E} \\
\Delta \mathrm{E} / \mathrm{E}_{0}(\mathrm{~T}) \\
(\%)\end{array}$} & \multicolumn{2}{|c|}{$\begin{array}{c}\text { Changes in Electrical } \\
\text { Resistivity }(\%)\end{array}$} \\
\hline & $\mathrm{E}_{0}(\mathrm{~L})$ & $\mathrm{E}_{0}(\mathrm{~T})$ & & & & $\Delta R / R(L)$ & $\Delta R / R(T)$ \\
\hline No.3-1 & 10.4 & 11.0 & 0.23 & -12.0 & -3.6 & +1.2 & 0 \\
\hline No.3-2 & 10.9 & 10.9 & 0.16 & -13.8 & -4.9 & +1.7 & 0 \\
\hline
\end{tabular}

$\mathrm{L}$ : parallel to the stress axis

$\mathrm{T}$ : perpendicular to the stress axis

Average compressive strength of IG-430U, $\sigma_{\mathrm{c}}=102 \mathrm{MPa}$

Table 3 Changes in Young's modulus of CX-2002U XXdirection (parallel to the stress axis).

\begin{tabular}{|c|c|c|c|c|}
\hline Specimen & $\begin{array}{c}\mathrm{E}_{0} \\
(\mathrm{GPa}) \\
*\end{array}$ & $\begin{array}{c}\text { Changes in } \\
\text { Density } \\
(\%)\end{array}$ & $\begin{array}{c}\text { Changes in } \\
\mathrm{E}(\%) \\
\left.\Delta \mathrm{E} / \mathrm{E}_{0}\right)\end{array}$ & $\begin{array}{c}\text { Changes in } \\
\text { Electrical Resistivity } \\
\Delta \mathrm{R} / \mathrm{R}(\%)\end{array}$ \\
\hline XX-dir. & 7.6 & 0.1 & -13.4 & -12.9 \\
\hline ZZ-dir. & 1.9 & & -4.3 & -4.9 \\
\cline { 1 - 3 } & & &
\end{tabular}

* : The values were determined by the mechanical test with strain gages. Avcrage compressive strength of CX-2002U (XX), $\sigma_{\mathrm{c}}=54 \mathrm{MPa}$

振動子と超音波探傷器（FD-1800, 三菱電機株)製）を用いて, 超音波伝播速度を求め, $\mathrm{E}=\rho \mathrm{V}^{2}$ からヤング率 $\mathrm{E}[\mathrm{GPa}]$ を算出 した。ここで, $\rho$ は密度 $\left[\mathrm{kg} / \mathrm{m}^{3}\right], \mathrm{V}$ は音速 $[\mathrm{m} / \mathrm{s}]$ である。

レーザーフラッシュ法により熱拡散率を測定するため, 圧 縮応力を付加した試験片から直径 $10 \mathrm{~mm}$, 厚さ $2 \mathrm{~mm}$ の円盤状 試験片をその軸方向が $30 \mathrm{~mm}$ の方向と一致するものおよび直 角方向のものを採取した。熱拡散率の测定は, 室温から 1300Kまでアルゴン雲讲気中で, レーザーフラッシュ型熱特 性測定装置（TC-7000S，(秼)真空理工製）を用いて行った。

比熱の温度依存性はButlandの式》)を用いて評価した。熱 伝導率 $\lambda[\mathrm{W} / \mathrm{mK}]$ は, $\lambda=\rho \mathrm{c} \kappa$ 加算出した。ここで, cは比 熱 $[\mathrm{J} / \mathrm{kgK}], \kappa$ は熱拡散率 $\left[\mathrm{m}^{2} / \mathrm{s}\right]$ である。

\section{3. 結果と考察}

微粒等方性黒鉛IG-430Uのヤング率, 密度と電気比抵抗に 及ぼす圧縮予応力の影響をTable 2に示す。室温で圧縮応力 を平均圧縮破壊応力の $90 \%$ まで付加した後, 荷重を除去して それぞれの特性を測定したものである。この表からわかるよ うに体積が若干減少し, したがって, 密度は増加する。ヤング 率は応力の付加方向とそれに垂直方向にも減少することがわ かる。しかし, 応力の付加方向の減少は $10 \%$ 以上と大きく, 一 方, 垂直方向は数\%程度の減少であった。これらの結果は以 前発表した結果4) と一致する。電気抵抗もわずかであるが増 加していることがわかる。

次に, C/Cコンポジット, CX-2002Uのヤング率, 密度, 電気 比抵抗に及ぼす圧縮予応力の影響をTable 3に示す。圧縮応 力はフェルト面 (XX) に平行に平均圧縮破壊応力の $90 \%$ を 付加した。その後, 応力を除去し, それぞれの特性を測定し, 変化を見たものである。黑鉛の場合と同様に密度がわずかに 増加している。ヤング率は応力の付加方向に大きく減少し,

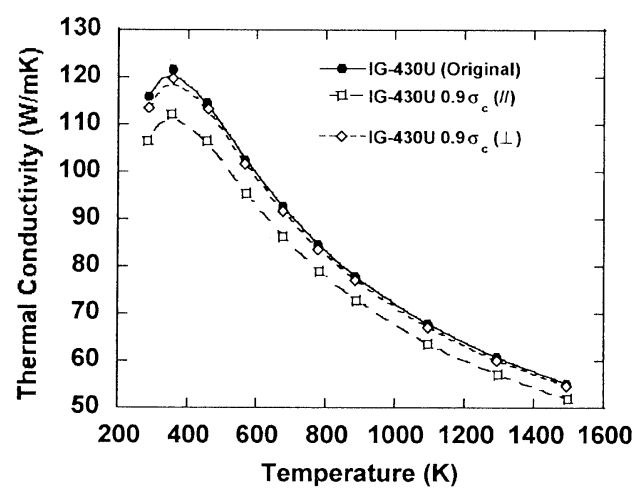

Fig.1 Effect of compressive prestress on the thermal conductivity of IG-430U graphite as a function of temperature.

応力の付加方向に垂直な方向にも数\%減少している。これら の結果は, 黑鉛の場合について, 以前発表した結果2)-5) と同様 であった。

圧縮応力を付加した後のヤング率の減少は, 微小き裂の発 生, 結晶子の回転等のために生じたものと考えられる4)。すな わち, 黒鉛結晶の異方性がその原因となっており, 応力の付加 方向へ結晶子の基底面の方向に垂直な方向が並んでくる傾向 があるためと思われる。このことは, C/Cコンポジットにつ いても同様の効果を与えるものと考えられる。

黒鉛IG-430UとC/CコンポジットCX-2002Uの2種類の材料 について圧縮応力を破壊応力の $90 \%$ まで付加した後応力を除 去し, 直径 $10 \mathrm{~mm}$, 厚さ $2 \mathrm{~mm}$ の円盤状試験片を採取して熱拡散 率をレーザーフラッシュ法によって測定した。応力の方向が 円盤の軸方向と同じ方向のものをXX方向とし, 垂直方向のも のをZZ方向とした。IG-430U黒鉛の熱伝導率の温度依存性 に及ぼす圧縮子応力の影響をFig.1に示す。応力の付加方向 に平行方向の熱伝導率を(II) で表し, 垂直方向の熱伝導率を （上）で表している。この図から明らかなように, 測定した温 度範囲において, 熱伝導率は圧縮予応力を付加することによ って減少することがわかる。予応力の付加方向には, $7.3 \%$ 減 少した。しかし, 予応力の付加方向に直角な方向には $2.1 \%$ の 減少を示した。

C/Cコンポジット, CX-2002Uの熱伝導率の温度依存性に及 
ぼす羊迅總応力の影響をフェルト面に平行な方向について Fig.2に示す。熱伝導率は各温度で尒応力の付加方向 $(\mathrm{XX})$ に対して $5.8 \%$ の減少を示している。予応力の付加方向に垂 直な力问 (ZZ) については, Fig.3に示すように, やはり減少 するが, その割合は3.3\%であり,XX万向より,小さく, 黑鉛の 場合と闹様な結果となった。これらの熱伝導率の減少量は, 温度に大きく依存せず, ほぼ等しくなっているとみなすこと ができよう。そこで, 玨縮予応力の付加による平均的な熱伝 導率の減少率をヤング率の減少率とともに表にしたのが

Table 4である。これらの対応について次に考える。

炭素材料のヤング率はは, すでに述べたように, 密度を $\rho$, 音 速をvとすれば,

$E=\rho v^{2}$

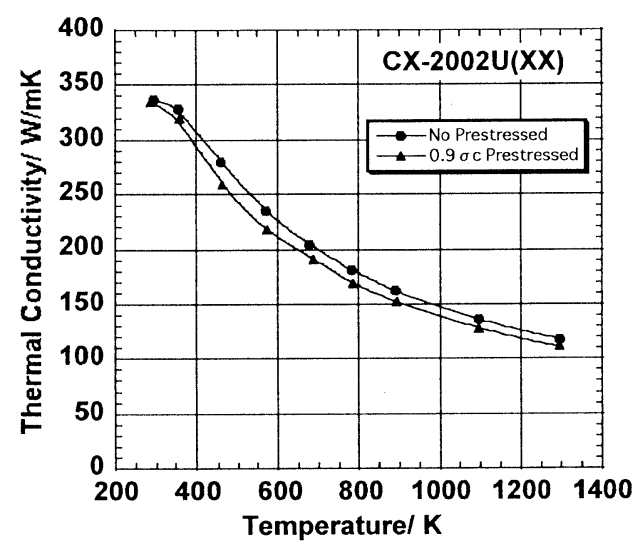

Fig.2 Effect of compressive prestress on the thermal conductivity of $\mathrm{C} / \mathrm{C}$ composite, $\mathrm{CX}-2002 \mathrm{U}(\mathrm{XX})$ as a function of temperature.

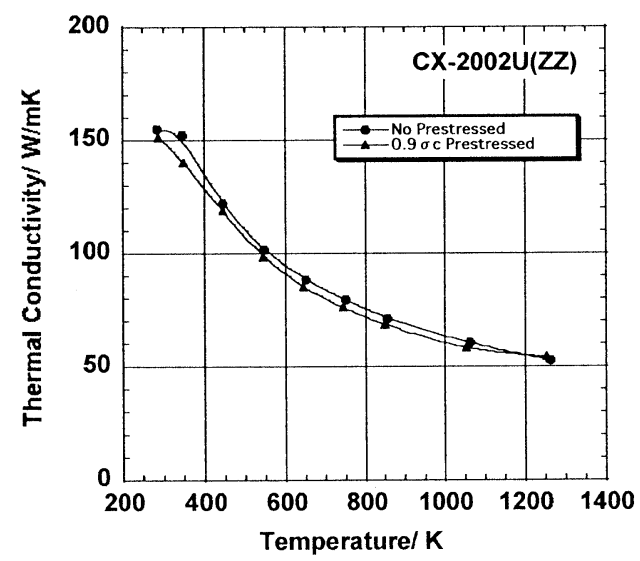

Fig.3 Effect of compressive prestress on the thermal conductivity of $\mathrm{C} / \mathrm{C}$ composite, $\mathrm{CX}-2002 \mathrm{U}(\mathrm{ZZ})$ as a function of temperature.

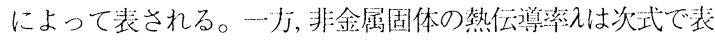
せることが知られている7〕。

$$
\lambda=\frac{1}{3} c_{v} v l
$$

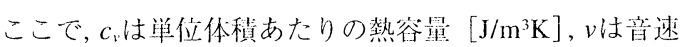
$[\mathrm{m} / \mathrm{s}], l[\mathrm{~m}]$ はフォノンの平均自由行程である。この式で $c_{v}$ の代わりに単位質量あたりの熱容量, すなわち前記の比熱 $[\mathrm{J} / \mathrm{kgK}]$ を用いてこの式を表せば,

$$
\lambda=\frac{1}{3} c \rho v l
$$

となる。この式が炭素材料に適用できるものと仮定し，これ らの式を基礎にして压縮予応力の影響を考えてみる。まず, 圧縮予応力を付加することにより，音速が減少する。これは 明白な実験結果であり，欠陷の增加すなわちフォノンの散乱 対象の増加によると考えられる。したがって，(2)，(2)'式か ら明らかなように, 音速の減少は熱伝導率の減少に寄与するは ずである。Table 2とTable 3から圧縮予応力によって密度が わずかに増加する。これはヤング率の増加に寄与するはずで あるが, これを考慮してもヤング率は減少することをTable 2 とTable 3は示している。今, 熱伝導率とヤング率との関係を 調べるため, (1) 式と (2) 式から音速を消去すれば, 次式が得 られる。

$$
\lambda=\frac{1}{3} c \rho l \sqrt{\frac{E}{\rho}}=\frac{1}{3} c l \sqrt{\rho E}
$$

したがって, 熱伝導率の変化率は次のようになる。

$$
\frac{\Delta \lambda}{\lambda}=\frac{\Delta c}{c}+\frac{\Delta l}{l}+\frac{1}{2}\left(\frac{\Delta \rho}{\rho}+\frac{\Delta E}{E_{0}}\right)
$$

圧縮予応力を付加することにより, 格子欠陥等を生じ, フォ ノンの散乱場所が増加することから平均自由行程は減少する 可能性がある。また, 比熱は構造鈍感な特性であり, 格子欠陥 等によってはほとんど変化しないと考えられるが,ここで行 った実験からこのことを示すことはできなかった。Table 2 〜Table 4に示すように, 本実験により, 圧縮予応力により密 度はわずかに増加し, ヤング率は減少することが確かめられ ている。IG-430U黑鉛については, ヤング率の変化に対して

Table 4 Correlation of changes in thermal conductivity with Young's modulus for IG-430U and CX-2002U materials.

\begin{tabular}{|c|c|c|}
\hline Material & $\Delta \mathrm{E} / \mathrm{E}_{0}(\%)$ & $\Delta \lambda / \lambda(\%)$ \\
\hline IG-430U $(\mathrm{L})$ & -12.0 & -7.3 \\
\hline IG-430U $(\mathrm{T})$ & -3.6 & -2.1 \\
\hline $\mathrm{CX}-2002 \mathrm{U}(\mathrm{XX})$ & -13.4 & -5.8 \\
\hline $\mathrm{CX}-2002 \mathrm{U}(\mathrm{ZZ})$ & -4.3 & -3.3 \\
\hline
\end{tabular}


密度变化は小さいがそれを平均して $0.2 \%$ とすれば, (4) 式仁巡 の第3 項はー5.9\%となり，したがって, Table 4から (4)式の第1 項と第2项の和はー $1.4 \%$ となる。つまり, 王綃予応力による比 熱の変化は不明であるが, 棈造に解感でないことを考えれば, もしあったとしてもフォノンの平均自由行程の変化はー1％程 度と推定される。しかし, 全体としては, ヤング率の变化が熟 伝槳率の変化に大部分寄与していると考えてよい。

次に, CX-2002Uについては, XX方向とZZ方向で, 黑鉛の 場合と類似の傾向を示している。すなわち, 応力の付加方向 については, 黒鉛と同様に(4) 式で考えると右辺第1項と第2 項の和は $0.9 \%$ となり,やはり, ヤング率の変化が熱伝導率の 変化に大部分寄与していると考えられる。しかし，応力の付 加方向に垂直な方向については，(4)式の第1項と第2項の和 は一 $1.2 \%$ となるので, 黒鉛の場合と同じような寄与すなわち フォノンの寄与がー $0.1 \%$ 程度ある可能性がある。

\section{4. 結 論}

微粒等方性黑鉛とフェルト型C/Cコンポジットのヤング率 と熱伝導率に及ぼす圧縮予応力の影響を検討した結果, 次の ような結論が得られた。

炭素材料のヤング率と熱伝導率は圧縮予応力を付加するこ とにより，一般に減少する。黒鉛の場合，再者の間には，音速 を通じて一定の関係があり, 压縮予応力により, 音速が減少 し，それか唡特性に影響を与えることすなわち,ヤング率も熱 伝尊率も減少することが明らかとなった。さらに, それらの

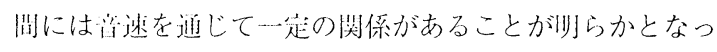
た。熱伝導摔の变化の大部分はヤング摔の変化によるものと

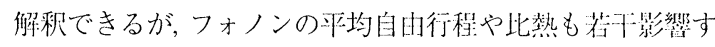
る问能性があることが指摘された。

C/Cコンポジットの場合, 応力の付加方问に平行な力问に ついては, 熱伝導率変化の大部分がヤング率の変化によるも

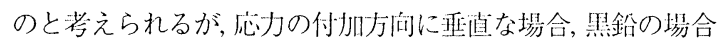
と同じ傾向を示すことが明らかになった。

\section{謝 辞}

本吥究は, 科学研究費特定領域研究No.288「カーボンアロ イ」の援助の下で行われた。試験用材料は東洋炭素秼から提 供された。ここに, 感謝の意を表する。

\section{文 献}

1) Par Ph. P. Arragon and R.M. Berthier, Industrial Carbon and Graphite (1958) p.565.

2) T. Oku and M. Eto, Carbon 11 (1973) 639.

3) T. Oku, T. Usui, M. Eto and Y. Fukuda, Carbon 15 (1977) 3.

4) T. Oku, S. Ota, M. Shiraishi, M.Eto and Y.Gotoh, Trans. of the Japan Society of Mechanical Engineers, (A) 61 [590] (1995) pp.2185-2189 [in Japanese].

5) T. Oku, A. Kurumada, Y. Imamura, K. Kawamata, M. Shiraishi, J. Nucl. Mater. 258-263 (1998) 814-820.

6) T.Saito and T. Oku, TANSO 1977 [No.91] 129-133 [in Japanese].

7) 高橋洋一, 「改訂炭素材料入門」(1984) p.55. 